\title{
Quiz
}

\section{Bilateral massive ovarian edema: A case report}

Khoiwal et al. Bilateral massive ovarian edema

Kavita Khoiwal, Payal Kumari, Om Kumari, Jaya Chaturvedi, Prashant Durgapal

All India Institute of Medical Sciences, Rishikesh, India

Adress for Correspondence: Kavita Khoiwal e-mail: kavita.kh27@gmail.com ORCID: orcid.org/0000-0002-3156-7486

DOI: 10.4274/jtgga.galenos.2020.2019-0202

Received: 14 December, 2019 Accepted: 27 April, 2020

\section{What is your diagnosis?}

An unmarried girl aged 17 years presented to our outpatient department with abdominal distension, dull aching abdominal pain, and amenorrhoea since 3 months. She attained menarche at 15 years of age and her previous menstrual cycles were regular with average flow. General physical examination was within normal limit. Abdominal examination revealed a firm, non-tender, mobile abdominopelvic mass corresponding to 22 weeks of uterus size. Ultrasound (USG) showed a large solid cystic right adnexal mass with internal septations. In view of suspicion of ovarian malignancy, tumor markers were ordered. The serum values of Ca-125 (28.5 U/ml), CA19.9 (24.6 U/ml), CEA (0.67 ng/ml), AFP (1.5 $\mathrm{IU} / \mathrm{ml}), \mathrm{HCG}(1.2 \mathrm{mIU} / \mathrm{ml})$ were within normal limit and LDH (403 U/l) was raised. CECT abdomen \& pelvis (Figure 1) suggested a well defined solid multi-cystic abdominopelvic mass lesion $(20.7 \times 14.6 \times 14 \mathrm{~cm})$ arising from right adnexa with enhancing septations and hyper dense component probably ovarian adenocarcinoma. Right ovary was not seen separately. Uterus was normal in size and left ovary was not seen properly. These findings led to a high clinical suspicion of ovarian malignancy and a plan of conservative staging laparotomy with right salpingo-ovariotomy was made in conjunction with oncology department.

\section{Answer}

Laparotomy was performed, intraoperative findings were suggestive of bilateral ovarian masses, an $8 \times 6 \mathrm{~cm}$ solid cystic left ovarian mass and 10x8 cm multi cystic right ovarian mass (Figure 2). Left sided mass was appeared to be malignant with no salvageable ovarian tissue. Left salpingo-ovariotomy and right sided cyst drainage followed by excision of cyst wall was performed. Cut section of left ovarian mass showed both solid and cystic areas containing clear fluid, solid area appeared white (Figure 3). Right ovary had multiple clear fluid filled cystic areas. Intraoperative frozen section was suggestive of serous cystadenoma. Postoperative course was uneventful. Final histopathological (HPE) examination of left ovary and right ovarian cyst wall revealed ovarian parenchyma with markedly loose and 
oedematous stroma, luteinisation of follicular cells, areas of hemorrhage and no atypia suggestive of massive ovarian edema (Figure 4).

Massive ovarian edema (MOE) is defined as an accumulation of edema fluid in the stroma, separating normal follicular structures by World health organization [1]. It is a rare entity, first reported in 1969 by Kalstone [2].

Most of the cases are presented among reproductive age group women but also reported in a 6-month-old girl and in a post-menopausal woman [3,4]. Almost $85 \%$ of these cases are unilateral, bilateral MOE is rarer [5]. Patient usually presents with pain abdomen along with palpable adnexal mass. [6]. Hormonal symptoms such as menstrual irregularity, precocious puberty, infertility and virilization may be associated due to stromal hyperplasia [5].

Exact pathogenesis behind its occurrence is still unknown but may be because of partial or complete ovarian torsion secondary to PCOS, fibrothecoma, metastatic carcinoma has been reported in literature [2-4,7-9]. When there is no underlying ovarian pathology, it is termed as primary MOE. We could not find any underlying cause, makes it a case of primary MOE. USG findings are inconclusive in most of the cases. MRI has been found successful in diagnosing MOE which shows enlarged ovary with follicles around the ovary [10]. In our case, USG was inconclusive and CECT scan could not detect MOE. MRI was not advised as we did not suspect MOE. This is the reason why we are reporting this case as high clinical suspicion and awareness of the disease is crucial for optimal management.

Tumour markers are usually normal though raised LDH and Ca-125 has been found in cases of ovarian edema with Meig's syndrome and fibrothecomas [8,9].

Though it can be suspected preoperatively and intraoperatively but the final diagnosis is made only on HPE.

MOE usually mimics ovarian malignancy which results in over-treatment with salpingoovariotomy. The mainstay of treatment is wedge resection of ovary [5]. A high index of suspicion is crucial for correct diagnosis and to conserve fertility. Risk of recurrence and long term implications of MOE are yet to be studied.

Conclusion

Massive ovarian edema is a rare ovarian disorder mimicking ovarian malignancy. Most of these cases present in young girls and over treated. Awareness of the disease and a high index of suspicion is the key of successful outeome.

\section{References}

1. Roth LM, Tsubara A, Dietel M, Senzaki H. Miscellaneous tumors and tumor-like conditions of the ovary. In: Tavassoli FA, Devilee P, editors. Pathology and Genetics of Tumors of the Breast and Female Genital Organs, World Health Organization Classification of Tumors. Vol. 5. Lyon: IARC Press; 2003. p.182-190.

2. Kalstone CE, Jaffe RB, Abell MR. Massive edema of the ovary simulating fibroma. Obstet Gynecol 1969; 34(4): 564-71.

3. Natarajan A, Wales JK, Marven SS, Wright NP. Precocious puberty secondary to massive ovarian edema in a 6-month-old girl. Eur J Endocrinol 2004; 150(2): 119-23.

4. Shirk JO, Copas PR, Kattine AA. Massive ovarian edema in a menopausal woman. A case report. J Reprod Med 1996; 41(5): 359-62.

5. Houssein SG, Husslein H, Shore EM, Lefebvre G, Vlachou PA. Bilateral Massive Ovarian Edema Due to Chronic Torsion Treated with Conservative Laparoscopic Approach. Journal of Gynecologic Surgery 2018; 34(6): 327-330.

6. Praveen R, Pallavi V, Rajashekar K, Usha A, Umadevi K, Bafna U. A clinical update on massive ovarian oedema-a pseudotumour? E-Cancer Med Sci 2013; 7: 318. 
7. Guvenal T, Cetin A, Tasyurt A. Unilateral massive ovarian edema in a woman with polycystic ovaries. Eur J Obstet Gynecol Reprod Biol 2001; 99(1): 129-30.

8. Lacson AG, Alrabeeah A, Gillis DA, Salisbury S, Grantmyre EB. Secondary massive ovarian edema with Meig's syndrome. Am J Clin Pathol 1989; 91(5): 597-603.

9. Sakaki M, Hirokawa M, Horiguchi H, Wakatsuki S, Sano T, Izumi Y. Ovarian fibrothecoma with massive edema. J Med Invest 2000; 47: 148-151.

10. Umesaki N, Tanaka T, Miyama M, Nishimura S, Kawamura N, Ogita S. Successful preoperative diagnosis of massive ovarian edema aided by comparative imaging study using magnetic resonance and ultrasound. Eur J Obstet Gynecol Reprod Biol 2000; 89(1): 97-99.
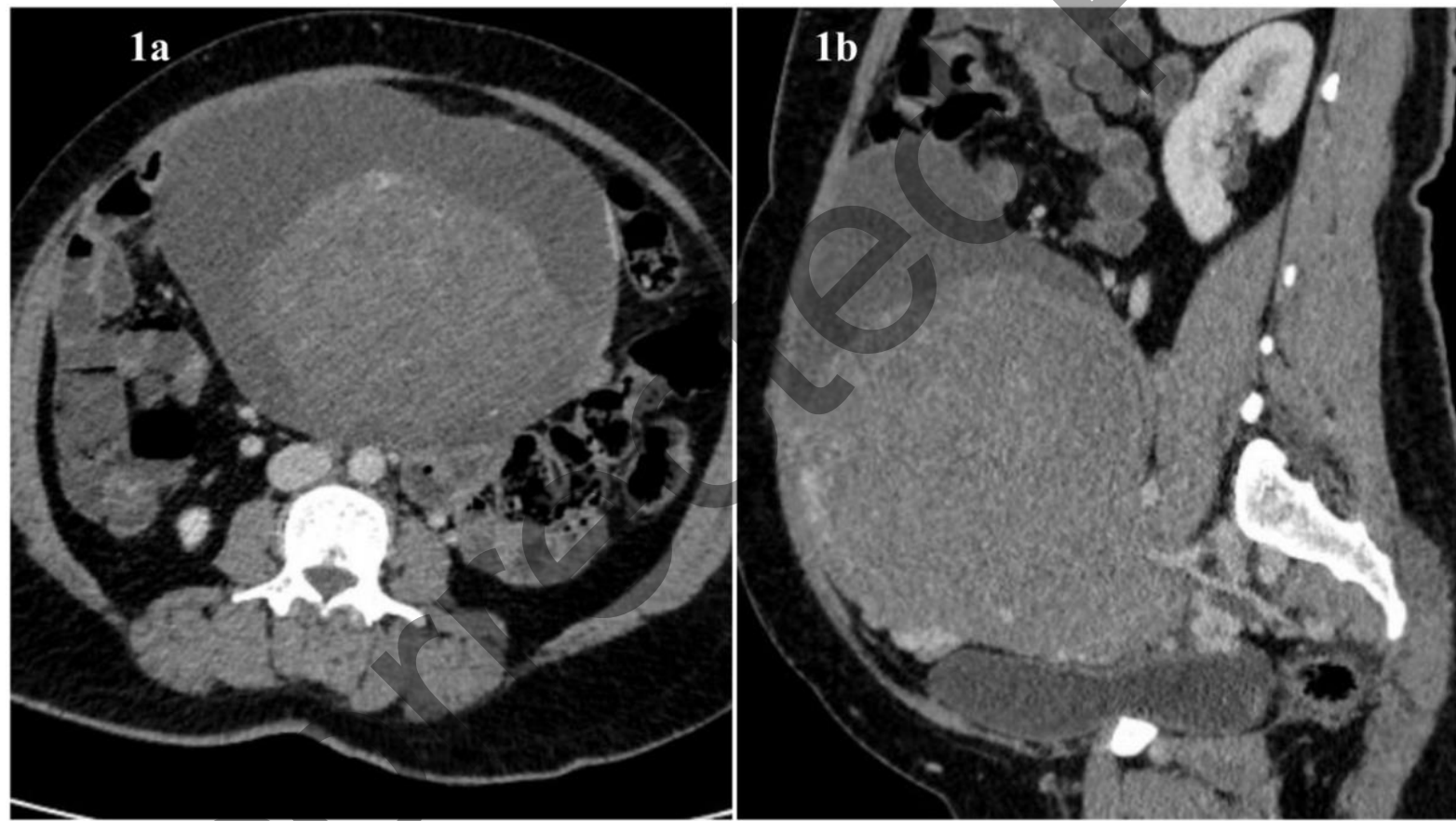

Figure 1. CECT abdomen \& pelvis showing a well defined solid cystic lesion of size $20.7 \times 14.6 \times 14 \mathrm{~cm}$ arising from right adnexa with solid component measuring $18 \times 14 \times 14 \mathrm{~cm}$ (1a:Transverse section, 1b:Sagittal section) 


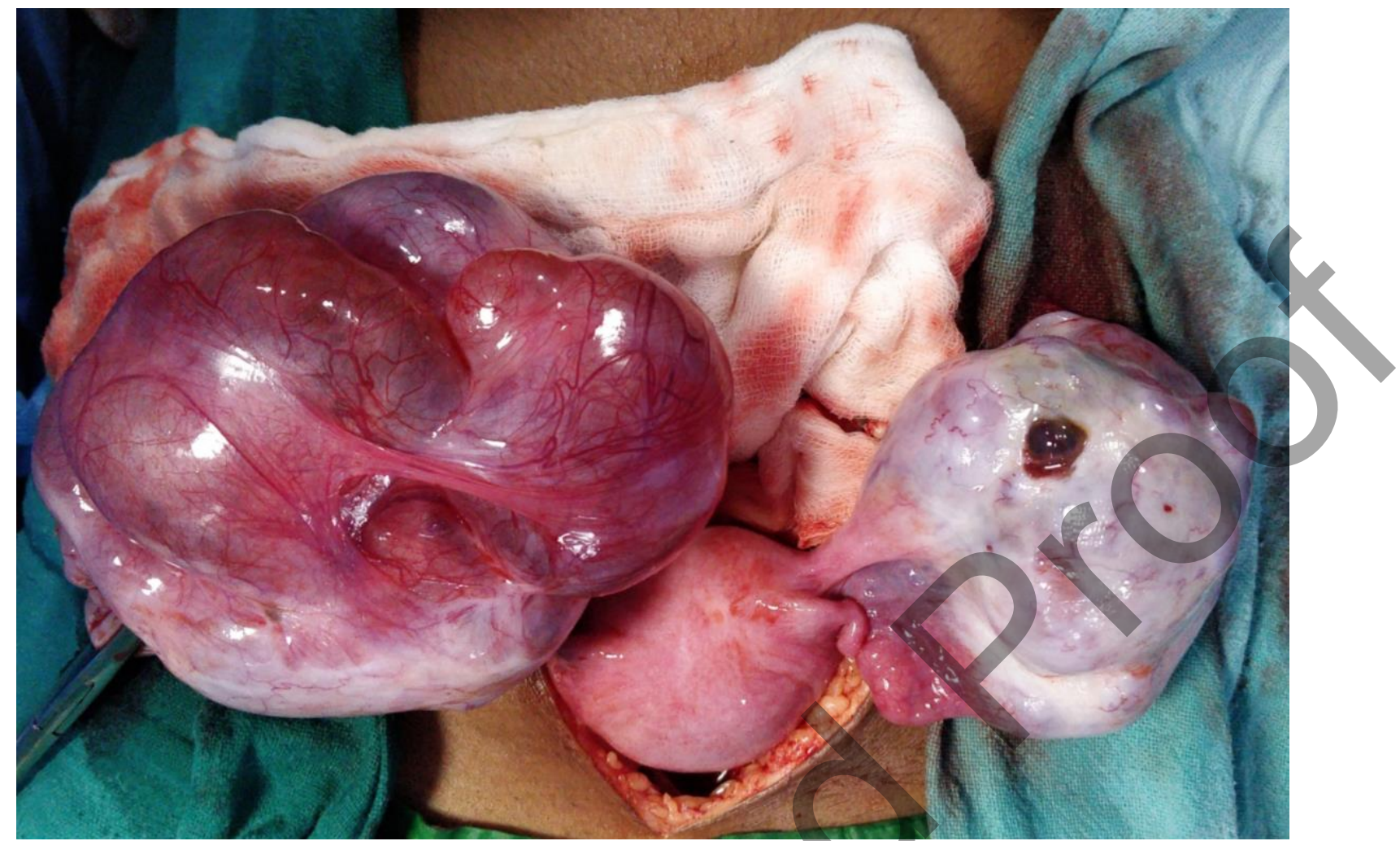

Figure 2. Intraoperative image suggestive of bilateral ovarian masses, a $8 \times 6 \mathrm{~cm}$ solid cystic left ovarian mass and an 10x8 cm multi cystic right ovarian mass 


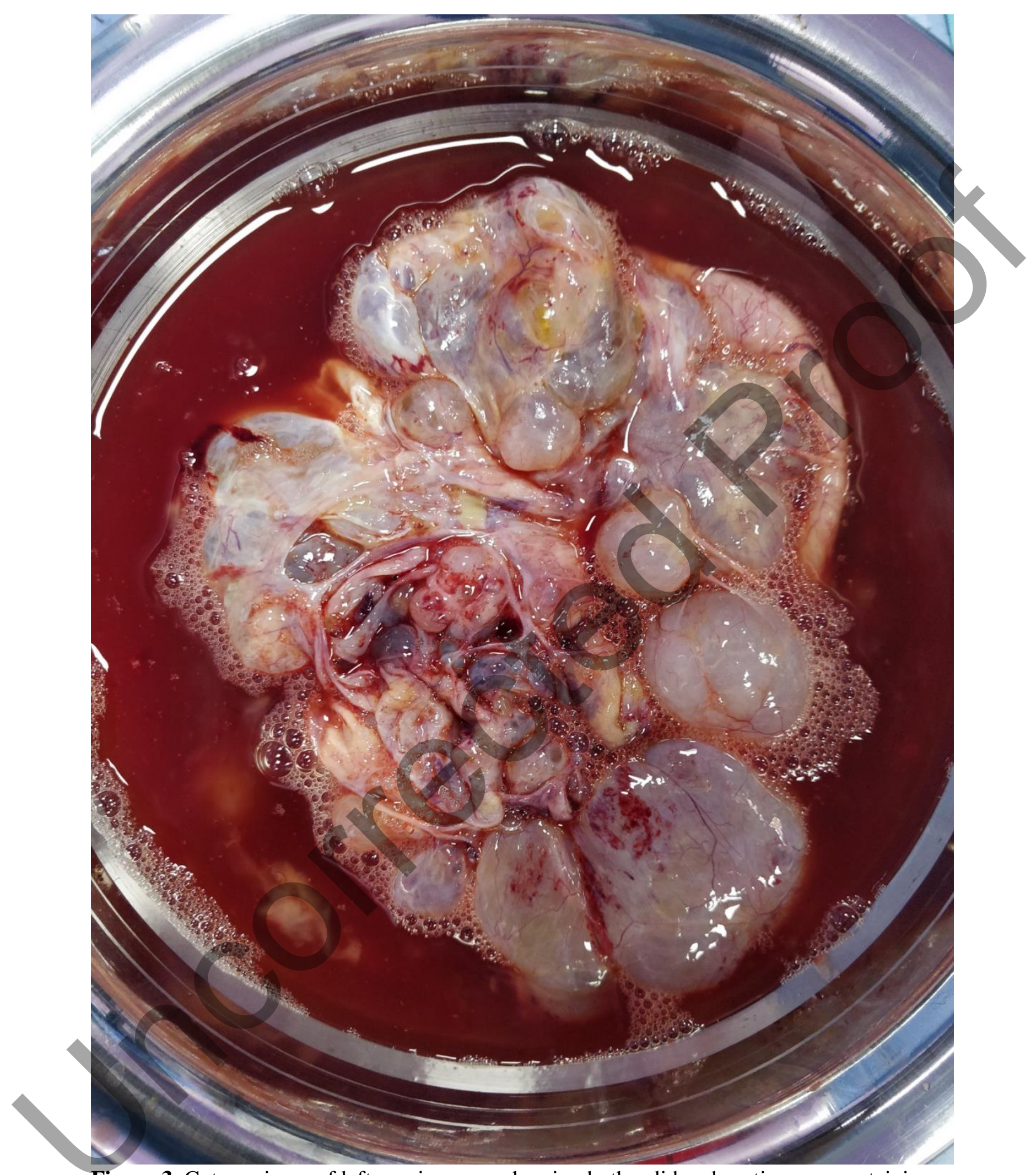

Figure 3. Cut specimen of left ovarian mass showing both solid and cystic areas containing clear fluid, solid area appeared white 


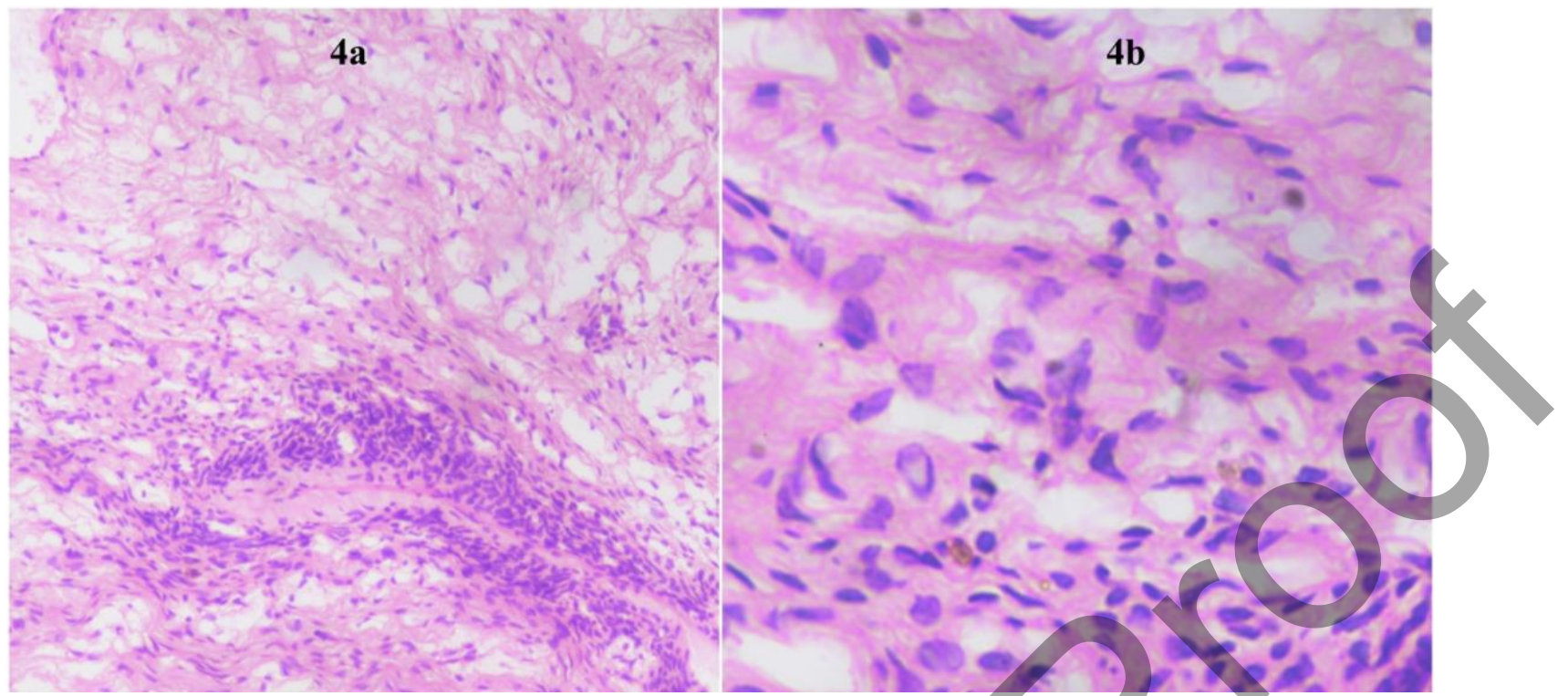

Figure 4. H\&E (x10 \& x40) stained section showing ovarian parenchyma with markedly loose and oedematous stroma, luteinisation of follicular cells, areas of hemorrhage and no atypia suggestive of massive ovarian edema 